\title{
Seabirds and demersal longliners in the northwestern Mediterranean: factors driving their interactions and bycatch rates
}

\author{
Verónica Cortés ${ }^{1, *}$, José Manuel Arcos ${ }^{2}$, Jacob González-Solís $^{1}$ \\ ${ }^{1}$ Institut de Recerca de la Biodiversitat (IRBio) and Departament de Biologia Evolutiva, Ecologia i Ciències Ambientals, \\ Facultat de Biologia, Universitat de Barcelona, 08028 Barcelona, Spain \\ ${ }^{2}$ SEO/Birdlife - Marine Programme, Delegació de Catalunya, 08026 Barcelona, Spain
}

\begin{abstract}
Bycatch mortality in longline fisheries is considered the main threat at sea for numerous seabird species. These incidental catches occur worldwide, but mortality levels are mainly determined by the specific traits of the fishery operating in each area and the feeding behaviour and local abundance of seabirds. In the Mediterranean, demersal artisanal longliners are known to catch several seabirds, but bycatch rates and the main factors influencing both the probability and the level of seabird bycatch are poorly known. From 2011 to 2015 we conducted 220 trips onboard demersal longline vessels of the Balearic Sea, aiming to study their interaction with seabirds, as well as to understand the detailed procedures of the fishery and the factors that might influence seabird bycatch. Additionally, we recorded bird catches reported by fishermen. We found an average overall bycatch rate of 0.58 birds per 1000 hooks $(0.13-1.37,95 \% \mathrm{CI})$, which would imply a conservative estimate ranging from 274 to 2198 seabirds caught annually on demersal longliners in the study area. The most affected species were the 3 endemic and threatened Scopoli's, Balearic and Mediterranean shearwaters of the Mediterranean (Calonectris diomedea, Puffinus mauretanicus and P. yelkouan, respectively), likely due to their highly aggregative behaviour and diving capabilities. Overall, the main factors influencing bycatch risk were season and time of day. Other influential factors were bait type, wind conditions, gear configuration (specifically, distance between weights), proximity to the breeding colony and the number of hooks. This study shows that mortality caused by demersal longliners is high and may be jeopardizing the viability of the shearwater populations. Therefore, the identification and implementation of mitigation measures is urgently required.
\end{abstract}

\footnotetext{
${ }^{*}$ Corresponding author: vecorse@gmail.com
}

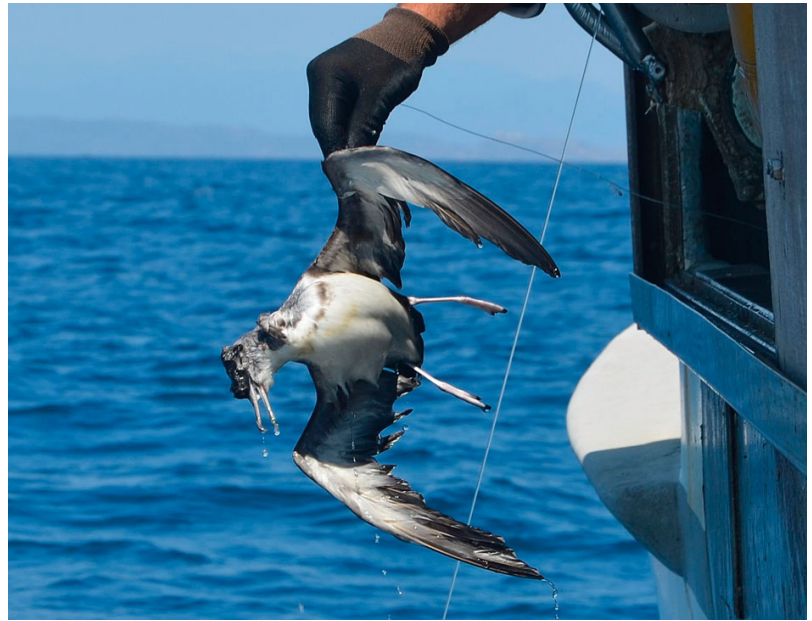

Puffinus shearwaters were the seabirds most susceptible to bycatch due to their remarkable diving capabilities.

Photo: Verónica Cortés

KEY WORDS: Artisanal fisheries • On-board observations · Mortality · Mitigation measures · Susceptibility to capture $\cdot$ Shearwaters

\section{INTRODUCTION}

Fishing is considered one of the most serious threats to seabirds worldwide, both through bycatch and the over-exploitation of fish prey (Tasker et al. 2000, Croxall et al. 2012). Bycatch in longline fisheries mainly occurs when birds try to steal bait from the hooks while the line is being set. During these attempts, seabirds can become entangled or hooked, and die by drowning when the gear sinks (Brothers

() The authors 2017. Open Access under Creative Commons by Attribution Licence. Use, distribution and reproduction are unrestricted. Authors and original publication must be credited. 
et al. 1999a). Globally, at least 160000 seabirds are killed annually in longline fisheries, most of them albatrosses (Diomedeidae), petrels and shearwaters (Procellaridae) (Anderson et al. 2011). Many of these species are threatened, and bycatch has significantly contributed to dramatic declines of their populations (Weimerskirch et al. 1997, Inchausti \& Weimerskirch 2001, Lewison \& Crowder 2003, Wanless et al. 2009). This is especially so since bycatch influences adult survival, the most sensitive demographic parameter for long-lived organisms with low fecundity and delayed maturity, such as seabirds (Weimerskirch 2002).

Collecting data through on-board observations is the first step to quantifying bycatch and identifying the main drivers affecting bycatch rates. Many factors potentially influence the degree of seabird interactions with longline vessels, such as operational characteristics, type and configuration of the fishing gear, weather conditions at setting and the seabird species present in a given area (Brothers et al. 1999b, Weimerskirch et al. 2000, Gilman 2001, Dietrich et al. 2009). Understanding the relative importance of these factors is crucial to managing and implementing best practices to reduce bycatch for a specific longline fleet and area (Brothers et al. 1999a).

Seabird bycatch is well documented in some regions, such as the Southern Oceans and North Pacific, where industrial longline vessels operate (Brothers 1991, Weimerskirch et al. 2000, Gales et al. 1998). Observer programmes conducted in these regions have allowed the development of mitigation measures adapted to the regional fleets to minimize the incidence of bycatch (Brothers et al. 1999a, Gilman et al. 2003, Løkkeborg 2011). Nonetheless, seabird bycatch rates in many longline fleets are still largely unknown, especially in semi-industrial and artisanal fleets (Anderson et al. 2011). One of the major gaps of knowledge is in the Mediterranean Sea, where longline fishing is arguably the main cause of seabird mortality and possibly the most important factor contributing to the decline of some seabird populations (Cooper et al. 2003, Arcos et al. 2008, Laneri et al. 2010, Genovart et al. 2016). Despite this, fishermen in this area still do not use any mitigation measures to reduce seabird catches. Previous studies in Spain estimated bycatch rates at ca. 0.013-0.049 birds per 1000 hooks in the semiindustrial pelagic longliners (Valeiras \& Camiñas 2003, Barcelona et al. 2010). These figures can be considered relatively low, but several characteristics of this fleet make it less problematic compared to artisanal demersal longliners, which use smaller hooks baited with the most common seabird prey in the area, such as sardine Sardina pilchardus. Information from these artisanal fisheries is scarce, but supports the view that they can have a higher impact on seabirds than semi-industrial pelagic longliners. Indeed, a previous study on artisanal demersal longliners operating around the Columbretes Islands showed high mortality rates, reaching up to 0.16-0.69 birds per 1000 hooks (Belda \& Sánchez 2001). However, mortality estimates assessed in a small area cannot be extrapolated to other areas because bycatch rates are highly variable locally, due to differences in bird abundances and longline fleet characteristics (Valeiras \& Camiñas 2003, Lewison et al. 2014). Therefore, reasonably broad spatial and temporal coverage of on-board observer programmes is required to obtain accurate and reliable bycatch estimates (Gilman et al. 2005, Anderson et al. 2011).

This study provides the first comprehensive data on seabird bycatch by the artisanal demersal longliners operating throughout the entire Balearic Sea (northwestern Mediterranean) based on on-board observations. Our main objectives were to (1) characterize the Spanish Mediterranean demersal longline fishery; (2) determine the degree of interaction with longliners for the different species of seabirds; (3) assess the factors influencing seabird attempts to take bait (taken as a proxy of bycatch risk); and (4) estimate the bycatch mortality of this fleet for the study area.

\section{MATERIALS AND METHODS}

\section{Study area}

The study was performed in the Balearic Sea (Fig. 1), which includes the Balearic Islands and the northeastern Iberian waters (Catalonia and north of the Valencian region), and marginally extends southwards across the south of the Valencian region. The area holds important seabird breeding colonies, including the entire global population of the Balearic shearwater Puffinus mauretanicus and the bulk of that of Audouin's gull Larus audouinii, as well as important populations of Scopoli's shearwater Calonectris diomedea (Martí \& Del Moral 2003). Other breeding species of relevance include the European storm petrel Hydrobates pelagicus, the Mediterranean shag Phalacrocorax aristotelis desmarestii and the yellow-legged gull L. michahellis. All of these species have important foraging grounds in the region, particularly over the Iberian shelf, which also attracts breeding birds from colonies beyond the 


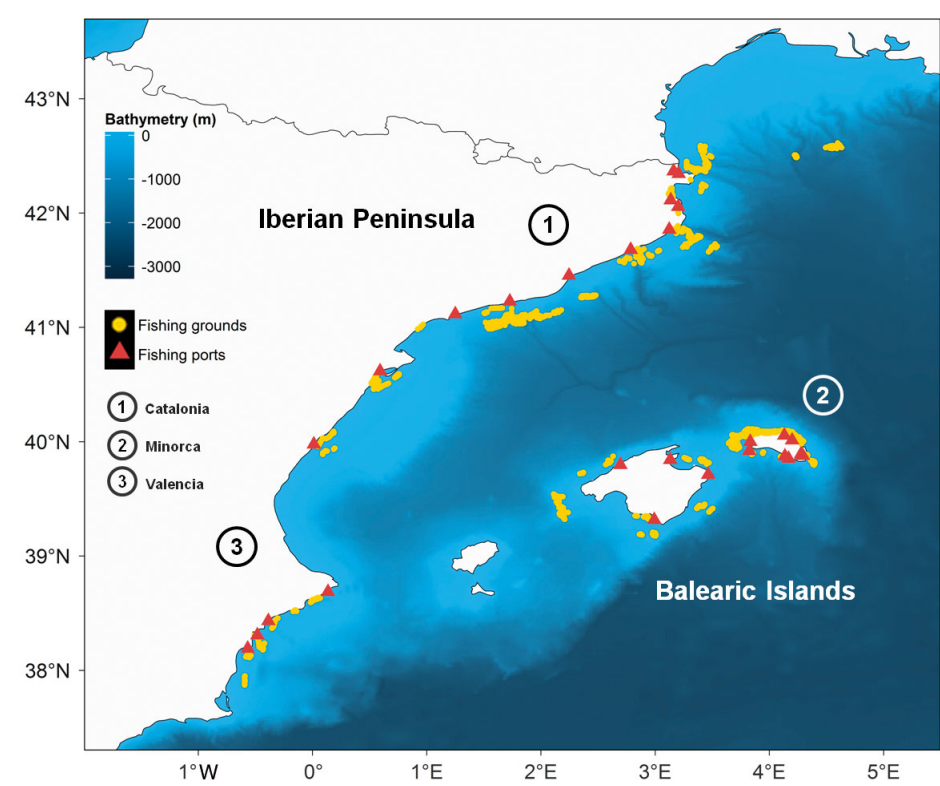

Fig. 1. Fishing grounds in the northwestern Mediterranean in which on-board observations were performed during the study period

study area, particularly Mediterranean and Scopoli's shearwaters (Arcos et al. 2012, Péron \& Grémillet 2013, Péron et al. 2013).

The demersal longline fleet in the region consists of artisanal boats ranging from 7 to $15 \mathrm{~m}$ in length and 1 to 4 crew members. This artisanal fleet is very heterogeneous and dynamic, with high variability regarding longline configuration and fishing practices, mainly linked to the species targeted and the specific fishing habits of each skipper. Overall, the fleet can be divided into 2 major groups: medium-scale longliners and small-scale vessels. Basic differences between these groups are the distance from the coast where they fish, the type and size of hook and bait, the number of hooks that are set and the longline length. Moreover, small-scale vessels are polyvalent, so they can alternate among different gears throughout the year, such as longline, gillnets, trammel nets or traps. Medium-scale longliners are mainly concentrated on the Catalan coast (11 boats in 2015; Generalitat de Catalunya pers. comm.), with another 6 boats in the Valencian region (in 2015; www.agroambient. gva.es) and only 3 in the Balearic Islands (in 2014; Govern de les Illes Balears pers. comm.). Their activity is reported to the administration, so it was possible to estimate the dimension and fishing effort of the fleet. On the other hand, small-scale vessels are not bound to report on the type of gear used, so their effort is little known. They represent the most important fleet in the Balearic Sea, reaching a few hundreds of boats operating in each sub-region.

\section{Data collection}

Observations on board demersal longliners were carried out across the Balearic Sea during 220 fishing days (103 in medium-scale and 117 in small-scale vessels), from January 2011 to January 2015. These comprised 35 artisanal vessels (11 medium-scale and 24 small-scale vessels) from 26 fishing ports. Observation trips were organized attempting to cover the main fishing grounds of the longline vessels in the study area year-round. Detailed descriptions of the fishing gear and practices (e.g. operational characteristics, fishing grounds, target species), were documented for each fishing trip. Specifically for each setting operation, the position, time of day, meteorological data and diverse fishing characteristics were recorded. In addition, observers registered at $10 \mathrm{~min}$ intervals all seabirds that followed the vessels during line setting. For each time interval, the number and distance astern of all attacks on bait performed by each seabird species were also registered and were ranked in 6 intervals: <5, 5-10, 11-20, 21-50, 51-100 and $>100 \mathrm{~m}$. In the night settings, counts of birds and attacks were limited by the distance from the stern at which they could be detected, given the illumination provided by the boat. All seabirds bycaught were recorded specifying the species, location and time of catch, when it was possible to recover the bird hooked.

During the $4 \mathrm{yr}$ of study, fishermen also provided information on seabird catches that occurred when no observers were onboard. In some cases, they collected seabird carcasses which allowed us to confirm the species identification. Although these observations were collected irregularly and opportunistically, this information helped us to understand the occurrence, species involved and the main periods of multiple-catch events; an understanding that would have been difficult to obtain solely from the on-board programmes due to the irregularity of the events.

\section{Data analysis}

Factors affecting seabird attack rates. During this study, we did not register sufficient bird catches to properly assess what factors have an important influence on bycatch. Instead, we used the number of attacks on baited hooks as a proxy of bycatch risk, 
since it reflects the direct interaction with the longline gear. This assumption was supported by the positive and significant correlation between bycatch and attack numbers, both when we considered all settings monitored $\left(\mathrm{r}_{\mathrm{S}}=0.42, \mathrm{p}<0.001, \mathrm{~N}=309\right.$ settings $)$ and only those in which there were seabird catches $\left(\mathrm{r}_{\mathrm{S}}=0.71, \mathrm{p}<0.001, \mathrm{~N}=24\right)$.

Generalized linear mixed models (GLMMs) were used to identify the main factors affecting seabird attack rates. Analyses were conducted considering 2 groups: (1) all seabird species together and (2) only Scopoli's shearwaters, one of the species most commonly caught by the demersal longline fleet. In the latter case, we only considered those fishing trips performed during the period in which the species is present in the Mediterranean (March to October).

Count data are characterized by skewed distributions, as a result of a high proportion of zero values and a few events of large counts (flocking behaviour) (Fletcher et al. 2005). Hurdle models are a suitable method for modelling this type of distribution (Welsh et al. 1996, Fletcher et al. 2005, Zuur et al. 2009); these models are characterized by treating the data in 2 parts: (1) presence versus absence (Zero part); and (2) presence observations (Count part).

We analysed the relationship between the occurrence and number of attacks with temporal, spatial, meteorological and operational variables (Table 1). To assess its influence on seabird attraction to longliners, trawling activity was also considered, as previous studies found an important effect on seabird catches (Laneri et al. 2010, Báez et al. 2014, SorianoRedondo et al. 2016). Consecutive settings with the same fishing gear characteristics were grouped to avoid pseudoreplication. Vessel identity was included in all models as a random effect to control for the non-independence between sets within the same vessel. The number of birds following the boat was used as an offset in the count data. We only considered the line settings targeting demersal fish. Moreover, settings performed at night and with hooks baited with species of crustaceans and molluscs were not considered in the count data or in either 2 parts of the model due to the low number of events of attacks on bait. Likewise, trawler activity was not considered in the count data due to the low number of observations conducted when trawlers were not operating.

We applied the 'glmmadmb' function from the 'glmmADMB' package (R 3.0.1.). The Zero hurdle part was modelled assuming a binomial (BI) error structure (logit link function $=$ cloglog), while the Count part was analysed considering a truncated version of the Negative Binomial distribution (HNB). We explored the factors selected to check collinearity between them and to remove non-explanatory categories. We then used the variance inflation factor (VIF) to verify the independence of each variable in the estimate of the regression coefficients of the model (Zuur et al. 2010).

Finally, we constructed the following models (see detailed information about the factors considered in Table 1):

Table 1. Explanatory variables used in the analyses of the factors influencing seabird interaction with longliners in the northwestern Mediterranean Sea

\begin{tabular}{|c|c|c|}
\hline Factor & Type & Description \\
\hline \multicolumn{3}{|l|}{ Temporal } \\
\hline Season (all species) & Categorical & Winter (Dec-Feb), Spring (Mar-May), Summer (Jun-Sep), Autumn (Oct-Nov) \\
\hline \multicolumn{3}{|r|}{ ( } \\
\hline Distance to colony & Continuous & Kilometres from the nearest breeding colony (scaled) \\
\hline \multicolumn{3}{|l|}{ Operational } \\
\hline Bait type & Categorical & Fish, cephalopods, mixed (fish + cephalopods) \\
\hline Bait size & Categorical & Shorter or longer than $10 \mathrm{~cm}(\max .=20 \mathrm{~cm})$ \\
\hline Setting time (time) & Categorical & Night, within \pm 1 h of dawn, daytime \\
\hline Hooks set (hooks) & Continuous & Number of hooks set (scaled) \\
\hline Distance between weights & Continuous & Distance between the weights attached to the snoods (scaled) \\
\hline
\end{tabular}


All species:

Number of attacks $(\mathrm{HNB}) \sim$ season + wind + bait type + bait size + time + hooks + distance weights

Occurrence of attacks $(\mathrm{BI}) \sim$ season + wind + bait type + bait size + time + hooks + distance weights + trawler activity

\section{Scopoli's shearwater:}

Number of attacks $(\mathrm{HNB}) \sim$ period + distance to colony + wind + bait size + time + distance weights

Occurrence of attacks $(\mathrm{BI}) \sim$ period + distance to colony + wind + bait type + bait size + time + hooks + distance weights + trawler activity

Model selection was made using the modelaveraging process. This approach is useful when there is uncertainty about which is the best model (Burnham \& Anderson 2002). In this way we obtained model-averaged parameter estimates, taking into account the unconditional variation linked to the uncertainty of the model selection (Burnham \& Anderson 2002). We estimated the parameters using the $95 \%$ confidence set of the models where the sum of Akaike weights reached $>0.95$.

Seabird bycatch and mortality. Bycatch rate was expressed as the number of birds caught per 1000 hooks set. We calculated the average rate for each group of demersal longliners (medium and smallscale vessels), area (Iberia and Balearic Islands) and longline type. Confidence intervals $(95 \%)$ were determined using bootstrap re-sampling (10000 iterations) from observed data.

To estimate the mortality caused by the demersal longliners in the Balearic sea, we only considered the data collected in vessels from Catalonia (Iberia) and Minorca (NE Balearic Islands), as these areas had better spatial and temporal effort coverage allowing reliable estimates. For the medium-scale longliners, we only considered the bycatch rate obtained on the Catalan coast. Fishing effort was estimated using the data of annual fish landings from 2015 provided by the local administration (Generalitat de Catalunya). From this, we estimated the number of vessels operating in the area and the average number of fishing days per year (11 boats: 143 fishing days for each vessel and 3141281 hooks set by the entire fleet). For the small-scale vessels, we were only able to estimate mortality for Minorca. There we could collect data on the boats with sufficient detail to estimate fishing effort through surveys of fishermen (18 boats: 78 fishing days and 1534572 hooks). In the Iberian area, we did not have enough information to estimate the effort of these vessels; therefore it was not possible to evaluate the mortality caused by this fishery. In all cases, mortality estimates were only based on dead birds and did not include birds released alive.

To evaluate differences in bycatch susceptibility among species and longline type, we used the chi squared $\left(\chi^{2}\right)$ test to compare the proportion of birds caught during the observations onboard with the expected proportion of birds that could potentially be caught $(Y)$, as indicated by (1) the number of birds observed following vessels and (2) the observed number of attacks on baited hooks. The proportions were calculated as:

$$
Y_{i j}=\frac{n_{i j}}{N_{j}}
$$

where $n_{i}$ is the individual number of $i$ species for each $j$ source of data considered (attendance, attacks), and $N$ is the total number of all species vulnerable to bycatch.

\section{RESULTS}

\section{Characteristics of the demersal longline fishery}

The fishing grounds of the medium-scale demersal vessels stretched from 1.5 to 36 nautical miles (n miles) offshore (mean $\pm \mathrm{SD}=8.7 \pm 3.4$ ), at depths between 22 and $549 \mathrm{~m}$ (mean $\pm \mathrm{SD}=271.7 \pm 112.9)$. They manually set from 338 to 4800 hooks (1888 \pm 731) per fishing day at 1.2 to 10.5 knots $(5.04 \pm 1.58)$. The size of the hooks was $3.57 \pm 0.30$ and $1.64 \pm$ $0.26 \mathrm{~cm}$ of total length and of gape, respectively. In the case of the small-scale vessels, several boats used demersal longlines seasonally, mainly in accordance with the temporal pattern of fish abundance, market conditions and time closures of specific target species. However, a few vessels used longlines year round. Their fishing grounds were usually close to the coast, ranging from 0.3 to $19 \mathrm{n}$ miles $(2.3 \pm 1.7$, at depths between 7 and $609 \mathrm{~m}$ (mean $\pm \mathrm{SD}=81.8 \pm$ 71.7). They set from 147 to 2610 hooks $(957 \pm 538)$ each fishing day at 0.9 to 7 knots $(2.93 \pm 0.95)$. Hook sizes were $2.97 \pm 0.48 \mathrm{~cm}$ for overall length and 1.42 $\pm 0.41 \mathrm{~cm}$ for the gape.

For both vessel types, hooks were commonly baited with fish, usually sardine, European anchovy Engraulis encrasicolus and round sardinella Sardinella aurita, but sometimes with cephalopod species. Fishermen from the small-scale vessels frequently used smaller-sized bait, either because they cut fish into small pieces or baited with other small species of crustaceans and molluscs. Longlines were mainly set 
during daylight $(84 \%$ of the settings observed; $\mathrm{N}=$ $316)$, either at dawn $(48 \%)$ or during daytime $(36 \%)$, while setting at night was less frequent $(16 \%)$. The soak time (the time lapse between the setting and the hauling) of the longlines varied among vessels and target species. Most often longlines were hauled 1 to $2 \mathrm{~h}$ after setting, although some fishermen left longlines in the water for ca. $15 \mathrm{~h}$.

Irrespective of the type of vessel, longline configurations can be classified into 2 types according to the distribution of the hooks relative to the seabed: (1) the Piedra-Bola (PB) system (Fig. 2a,b), which is characterized by using a combination of weights and floats, so that hooks are kept at different depths, and (2) the bottom longline (Fig. 2c) which keeps the hooks level over the seafloor by only attaching weights to the snoods at regular intervals. The PB system may also be divided in 2 different sub-groups: the zigzag (Fig. 2a) and the pyramidal structure (Fig. 2b). The main differences between these structures are the distance between weights and the distance from the float to the nearest weight (Table 2), these being shorter in the zigzag structure. The zigzag structure was most commonly used by the medium-scale vessels $(78 \%$ of the fishing trips conducted), mainly employed for fishing European hake Merluccius merluccius and blackbelly rosefish Helicolenus dactylopterus. Pyramidal structures were less frequent $(8 \%)$ and were used to target blackspot seabream Pagellus bogaraveo. In addition, some fishermen occasionally used this structure for fishing pelagic species $(7 \%)$, such as Ray's bream Brama brama. In this case, they used larger floats and more weights attached to the branch lines $(5.4 \pm 2.4 \mathrm{~kg})$ placed at greater distances $(556.0 \pm 72.7 \mathrm{~m})$. Bottom longlines (Fig. 2c) were typically used in small-scale vessels $(86 \%)$ for fishing a wide diversity of demersal fish, such as common pandora Pagellus erythrinus, toothed bream Dentex dentex and gilt-head seabream Sparus aurata. In this type of fishing gear, we could distinguish 2 different longline configurations based on whether fishermen did or did not use weights attached along the mainline (Table 2; $50 \%$, bottom-weights; $36 \%$, bottom-no weights).

\section{Seabird species and abundance}

Seabirds were present in $67 \%$ of 316 settings monitored, totalling 1969 individuals from 16 species (Table 3), The most frequent species behind the vessels were Scopoli's shearwater (37\% of the sets), yellow-legged gull $(27 \%)$, Audouin's gull $(11 \%)$,
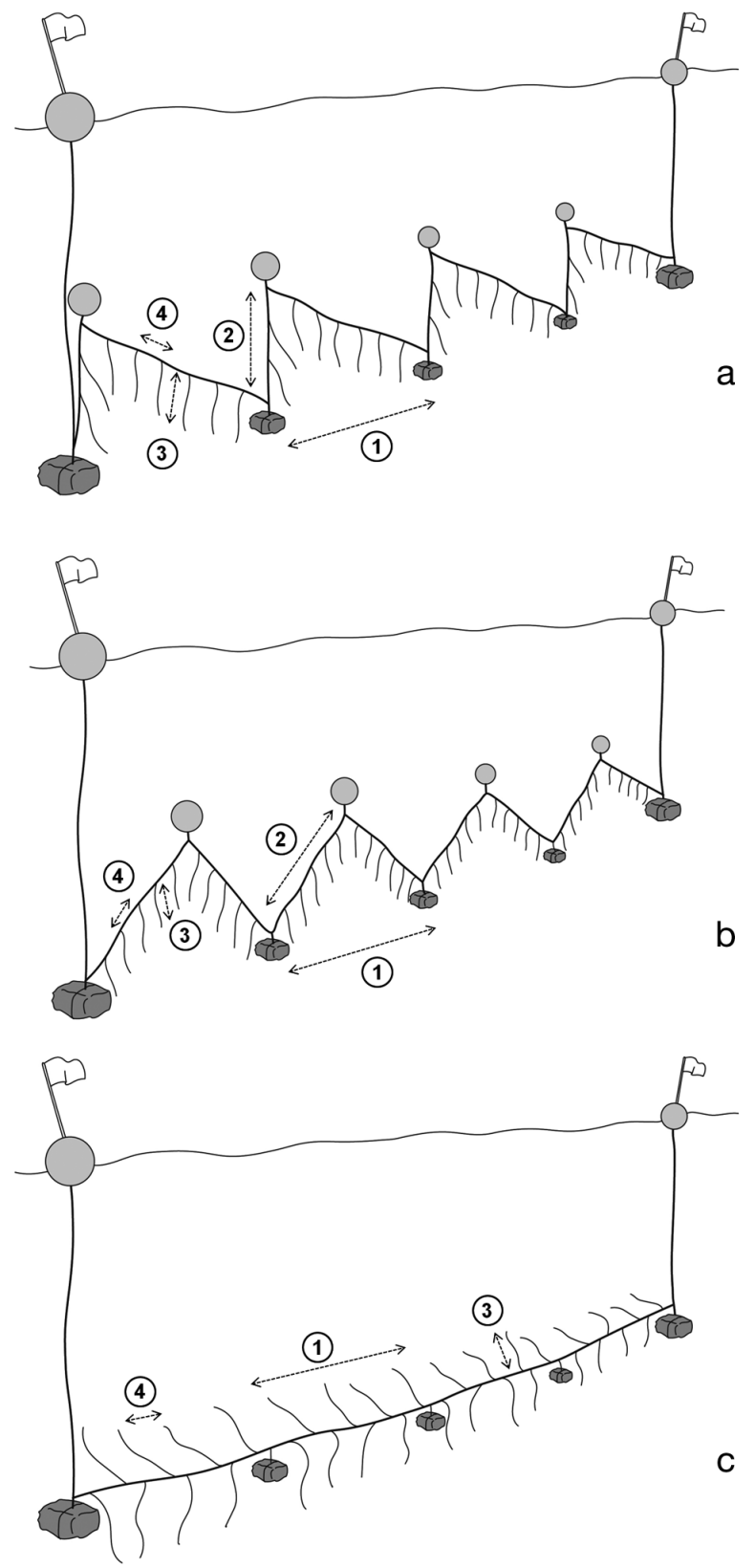

Fig. 2. Longline configurations used by the demersal fleet: $(\mathrm{a}, \mathrm{b})$ the Piedra-Bola system $(\mathrm{a}=$ PB-zigzag, $\mathrm{b}=$ PB-pyramidal) and (c) the bottom longlines (bottom-weights). 1 = distance between weights; $2=$ minimum distance between the weight and the float; $3=$ length of branch lines; $4=$ distance between hooks. Drawing by Toni Mulet

Balearic shearwater $(7 \%)$ and Mediterranean gull Larus melanocephalus (6\%).

Attempts to take baits occurred in $38 \%$ of the settings monitored, totalling 2180 events (Table 3). The main species involved in these attacks were Scopoli's shearwater $(58 \%)$, Balearic shearwater $(17 \%)$, yellow-legged gull $(10 \%)$ and Audouin's gull 
Table 2. Fishing gear characteristics of the most commonly used longline types by demersal longliners of the Balearic Sea. PB: Piedra-Bola configuration. Distance values and lengths are expressed in metres. Values correspond to mean \pm SD. Value in brackets refers to the number of fishing trips in which the fishing gear was used. Medium: medium-scale vessels ( $\mathrm{N}=103$ fishing trips), Small: small-scale vessels ( $\mathrm{N}=116$ fishing trips)

\begin{tabular}{|c|c|c|c|c|c|c|c|}
\hline \multirow{2}{*}{$\begin{array}{r}\text { Gear: } \\
\text { Type of vessel: }\end{array}$} & \multicolumn{2}{|c|}{ PB-zigzag } & \multicolumn{2}{|c|}{ PB-pyramidal } & \multicolumn{2}{|c|}{ Bottom-weights } & \multirow{2}{*}{$\begin{array}{l}\text { Bottom-no weights } \\
\text { Small }\end{array}$} \\
\hline & Medium & Small & Medium & Small & Medium & Small & \\
\hline \% usage and (n) & $78(80)$ & $10(11)$ & $8(8)$ & $4(5)$ & $14(15)$ & $50(58)$ & $36(42)$ \\
\hline Weight (kg) & $2.1 \pm 0.4$ & $1.2 \pm 1$ & $3.61 \pm 1.1$ & $0.5 \pm 0.1$ & $1.10 \pm 0.47$ & $0.8 \pm 0.8$ & - \\
\hline Distance between weights & $97.3 \pm 28.4$ & $113.6 \pm 32.0$ & $120.8 \pm 27.7$ & $201.4 \pm 242.8$ & $887.1 \pm 539.7$ & $411.3 \pm 364.0$ & - \\
\hline Min. distance of weight to float & $17.9 \pm 9.6$ & $30.6 \pm 12.2$ & $96.7 \pm 87.4$ & $101.4 \pm 122.8$ & - & - & - \\
\hline Length of branch lines & $1.92 \pm 0.1$ & $2.1 \pm 0.2$ & $2.0 \pm 0.0$ & $2.0 \pm 0.0$ & $1.3 \pm 0.7$ & $2.4 \pm 0.6$ & $2.2 \pm 0.29$ \\
\hline Distance between hooks & $3.9 \pm 0.9$ & $5.0 \pm 1.1$ & $3.5 \pm 0.6$ & $5.6 \pm 0.7$ & $6.0 \pm 1$ & $6.8 \pm 1.9$ & $6.2 \pm 0.44$ \\
\hline
\end{tabular}

(8\%) (Table 3). Considering only the settings performed during daytime $(\mathrm{N}=265)$, we found that most attacks occurred within 5 to $20 \mathrm{~m}$ behind the stern of the boat $(89 \%)$. For small-scale vessels, attacks mainly occurred at 5 to $10 \mathrm{~m}$ from the stern $(53 \%)$, while for medium-scale boats, the attacks were most frequent from 10 to $20 \mathrm{~m}$ (74\%). Regarding the gear configuration used (Fig. 3), for PB-zigzag, most attacks occurred from 10 to $20 \mathrm{~m}$ astern (85\%), while for bottom-weights attacks occurred more often at 5 to $10 \mathrm{~m}(61 \%)$. For the bottom-no weights, attacks also occurred in the first $10 \mathrm{~m}(40 \%)$, but were more frequent from 10 to $20 \mathrm{~m} \mathrm{(52 \% ).}$

\section{Factors influencing seabird attacks}

All species. Season and the bait used were the most important factors influencing the number of attacks (Table 4). The number of attacks was greater in spring and when fishermen used bait larger than $10 \mathrm{~cm}$, but it decreased when only fish bait was used. Moreover, the number of attacks was higher on windy days and with an increased number of hooks set. The occurrence probability of attacks was mainly influenced by the setting time, the season, and the bait type used; it increased in settings at dawn, during spring and when fishermen used fish bait. In addition, occurrence

Table 3. Number of birds (mean $\pm \mathrm{SD}$, total birds within brackets, $\mathrm{N}=316$ settings) of each species observed following vessels (attendance), species occurrence (\%, total occurrence days within brackets), number of bait attacks (mean \pm SD; total attacks within parentheses, $\mathrm{N}=298$ ) and occurrence of attack events ( $\%$, in parentheses number of days on which attacks observed) from the sets observed onboard demersal longliners

\begin{tabular}{|llcccc|}
\hline Common name & Taxon & No. attending & $\begin{array}{c}\text { \% bird } \\
\text { occurrence }\end{array}$ & No. of attacks & $\begin{array}{c}\text { \% attack } \\
\text { occurrence }\end{array}$ \\
\hline Scopoli's shearwater & Calonectris diomedea & $8.3 \pm 13.5(730)$ & $27.8(88)$ & $22.1 \pm 57.1(1280)$ & $19.13(57)$ \\
Balearic shearwater & Puffinus mauretanicus & $5.7 \pm 16.0(142)$ & $7.9(25)$ & $19.2 \pm 56.6(365)$ & $6.4(19)$ \\
Yellow-legged gull & Larus michahellis & $4.7 \pm 6.5(536)$ & $35.8(113)$ & $6.2 \pm 9.9(212)$ & $11.4(34)$ \\
Audouin's gull & Larus audouinii & $3.2 \pm 3.5(232)$ & $22.8(72)$ & $5.7 \pm 6.7(183)$ & $10.7(32)$ \\
Mediterranean shearwater & Puffinus yelkouan & $3.5 \pm 2.7(35)$ & $3.2(10)$ & $7.5 \pm 8.3(30)$ & $1.3(4)$ \\
Mediterranean gull & Larus melanocephalus & $3.1 \pm 3.1(107)$ & $11.1(35)$ & $1.6 \pm 1.4(13)$ & $2.7(8)$ \\
Small shearwaters & Puffinus spp. & $2.7 \pm 2.6(30)$ & $3.5(11)$ & $6.8 \pm 6.7(27)$ & $1.3(4)$ \\
Black-legged kittiwake & Rissa tridactyla & $2.7 \pm 2.4(38)$ & $4.4(14)$ & $4.9 \pm 5.2(44)$ & $3.0(8)$ \\
Sandwich tern & Sterna sandvicensis & $2.6 \pm 2.01(13)$ & $1.6(5)$ & $4.7 \pm 2.2(14)$ & $1.0(3)$ \\
European storm-petrel & Hydrobates pelagicus & $2.3 \pm 1.4(75)$ & $10.1(32)$ & 0 & 0 \\
Black-headed gull & Chroicocephalus ridibundus & $1.5 \pm 1.0(6)$ & $1.3(4)$ & $9 \pm 0.00(9)$ & $0.3(1)$ \\
Common tern & Sterna hirundo & $2(4)$ & $0.6(2)$ & 0 \\
Northern gannet & Morus bassanus & $1.2 \pm 0.5(6)$ & $1.6(5)$ & $1.3 \pm 0.6(4)$ & $1.0(3)$ \\
Great skua & Catharacta skua & $1(1)$ & $0.3(1)$ & 0 & 0 \\
Lesser black-backed gull & Larus fuscus & $1(3)$ & $1.0(2)$ & 0 & 0 \\
Pomarine skua & Stercorarius pomarinus & $1(1)$ & $0.3(1)$ & 0 & 0 \\
Great cormorant & Phalacrocorax carbo & $5(5)$ & $0.3(1)$ & 0 \\
\hline
\end{tabular}




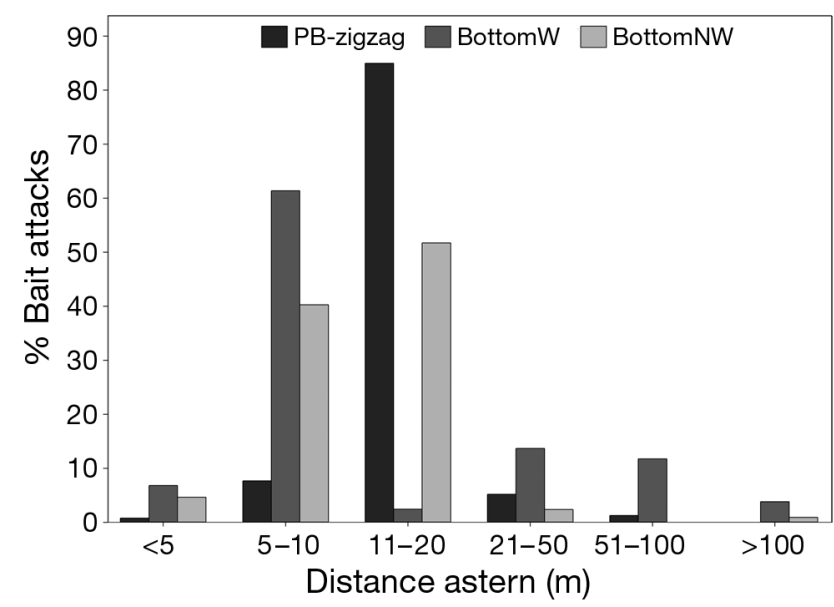

Fig. 3. Proportion of bait attacks (\%) performed by seabirds at different distance-intervals from the vessel stern considering separately the gear configurations most commonly used by demersal longliners of the study area. PB-zigzag = Piedra-Bola (zigzag configuration). BottomW = longline with only weights attached along the mainline (bottom-weights). BottomNW = longline without either weights or floats (bottom-no weights). Piedra-Bola and bottom longline configurations correspond to gear of the medium and small-scale vessels, respectively. The PB-pyramidal configuration was not considered here due to low sample size

probability was greater on windy days and at larger weight to weight distances.

Scopoli's shearwater. The number of attacks was greater in the pre-laying and incubation periods than during chick-rearing (Table 4), and also when larger bait was used. In addition, the number of attacks increased on windy days and with the distance between weights. The occurrence probability of attacks was mainly influenced by the setting time and the season; it increased during dawn settings and during the incubation period. Moreover, the occurrence probability was higher on windy days, but decreased with the increased distance to breeding colonies.

\section{Seabird bycatch and mortality}

Bycatch occurred in $9 \%$ of the settings monitored (12\% of the fishing days), totalling 109 birds of 7 species out of 342022 hooks observed (Table 5). In addition, 1 bird was caught during the hauling operations. Most birds were caught by the small-scale vessels $(81 \%)$ when comparing type of vessels, and in the bottom-weight configuration (55\%) when considering the gear type. However, most of these catches occurred in a single setting that caught 48 Puffinus spp. The remaining catches occurred in the bottom longlines without weights (25\%), PB-zigzag configuration (17\%) and in the PB-pyramidal configuration targeting pelagic fish $(2 \%)$. Overall average bycatch rate obtained in the study area was 0.58 birds per 1000 hooks $(0.13-1.37,95 \% \mathrm{CI} \mathrm{N}=211$ fishing trips). The highest bycatch rate was found in the small-scale vessels (Fig. 4), especially those from peninsular ports: 1.56 birds per 1000 hooks (0-4.67;

Table 4. Parameters estimated in the model averaging selection (coefficient values and unconditional standard errors) for each variable included in the 2 hurdle processes: Count (number of attacks) and Occurrence (presence probability of attacks), considering all seabird species and only Scopoli's shearwater Calonectris diomedea. RI: relative variable importance (sum of the Akaike weights from all models in the set where the factor occurs). Coefficient values denote the direction and the effect size. Parameters of the categorical factors (in italics) were calculated relative to the reference categories (coefficient takes the value 0): autumn (Season); prelaying (Period); calm (Wind); cephalopods (Bait type); bait size $<10 \mathrm{~cm}$ (Bait size); dawn/night (Time); weekend or trawling moratorium (Trawler activity).

Number of attacks in night settings was not considered in the analysis. The most important factors are indicated in bold

\begin{tabular}{|c|c|c|c|c|c|c|c|c|c|}
\hline \multirow[t]{2}{*}{ Fixed factors } & \multirow[t]{2}{*}{ Categories } & \multicolumn{4}{|c|}{ All species } & \multicolumn{4}{|c|}{ Scopoli's shearwater } \\
\hline & & Count & RI & Occurrence & RI & Count & RI & Occurrence & RI \\
\hline (Intercept) & & $-1.00 \pm 0.48$ & & $-2.86 \pm 0.69$ & & $-0.03 \pm 0.63$ & & $-3.24 \pm 0.78$ & \\
\hline Distance to colony & Number & - & - & - & - & $-0.43 \pm 0.31$ & 0.41 & $-0.71 \pm 0.35$ & 0.82 \\
\hline Bait size & $>10 \mathrm{~cm}$ & $0.85 \pm 0.25$ & 1 & $0.15 \pm 0.30$ & 0.28 & $1.59 \pm 0.48$ & 1 & $0.44 \pm 0.42$ & 0.37 \\
\hline Time & $\begin{array}{l}\text { Dawn } \\
\text { Day }\end{array}$ & $\begin{array}{c}- \\
-0.35 \pm 0.22\end{array}$ & 0.51 & $\begin{array}{l}1.38 \pm 0.46 \\
0.75 \pm 0.49\end{array}$ & 1 & $\begin{array}{c}- \\
0.27 \pm 0.24\end{array}$ & 0.25 & $\begin{array}{r}1.50 \pm 0.69 \\
-0.24 \pm 0.79\end{array}$ & 1 \\
\hline Hooks & Number & $0.27 \pm 0.12$ & 0.79 & $0.17 \pm 0.12$ & 0.51 & - & - & $-0.13 \pm 0.23$ & 0.29 \\
\hline
\end{tabular}


Table 5. Number of seabirds caught during the on-board observations (2011-2015), by species, area and vessel type. Number of individuals recovered alive is indicated in brackets. No birds were caught in medium-scale vessels from the Balearic Islands (10350 hooks). Bycatch rate = number of birds per 1000 hooks (mean + CI 95\%). Mortality = number of birds killed annually as estimated from the bycatch rate obtained. Species binomials are given in Table 3

\begin{tabular}{|c|c|c|c|c|}
\hline \multirow[t]{2}{*}{ Species } & \multicolumn{2}{|c|}{$\longrightarrow$ Peninsula } & \multirow{2}{*}{$\begin{array}{l}\text { Balearic Islands } \\
\text { Small-scale } \\
\text { (68410 hooks) }\end{array}$} & \multirow{2}{*}{$\begin{array}{c}\text { Total } \\
\text { (342 } 022 \text { hooks })\end{array}$} \\
\hline & $\begin{array}{l}\text { Medium-scale } \\
\text { (218453 hooks) }\end{array}$ & $\begin{array}{c}\text { Small-scale } \\
\text { (44 } 809 \text { hooks) }\end{array}$ & & \\
\hline Balearic shearwater & 5 & - & $8(8)$ & 13 \\
\hline Mediterranean shearwater & 2 & $1^{\mathrm{a}}(1)$ & - & 3 \\
\hline Scopoli's shearwater & 5 & - & $27(5)$ & 32 \\
\hline \multicolumn{5}{|l|}{ Unidentified shearwater: } \\
\hline Puffinus spp. & 1 & $45^{\mathrm{b}}(3)$ & $2(2)$ & 48 \\
\hline Audouin's gull & 2 & - & $2(1)$ & 4 \\
\hline Yellow-legged gull & 3 & - & $4(1)$ & 7 \\
\hline Black-legged kittiwake & 2 & - & - & 2 \\
\hline Northern gannet & 1 & - & - & 1 \\
\hline Total & 21 & 46 & 43 & 110 \\
\hline Bycatch rate & $0.12(0.05-0.21)$ & $1.56(0-4.67)$ & $0.59(0.18-1.15)$ & $0.58(0.13-1.37)$ \\
\hline Mortality & 357 (126-642) & - & $675(148-1556)$ & $1,032(274-2198)$ \\
\hline
\end{tabular}

$\mathrm{N}=48$ ). However, this rate was obtained from only 1 mass catch event (Table 5). Small-scale vessels from the Balearic Islands also showed a high bycatch rate: 0.59 birds per 1000 hooks (0.18-1.15; $\mathrm{N}=65)$, with Scopoli's shearwater being the main species affected (Table 5). Concerning the longline configuration used, we found the highest bycatch rates in both types of bottom gear, especially in the longlines without weights (Fig. 4).

Most birds caught were recovered dead (81\%). Only in the small-scale vessels, due to their lower setting speed, was it possible for fishermen to stop and release hooked birds alive. On the other hand, these longliners normally set in shallower waters and their branch lines are long enough for birds to reach the surface and survive until hauling.

Fishermen reported 739 birds caught when we were not onboard, during the $4 \mathrm{yr}$ study period (Table 6). Most of these birds were shearwaters $(95 \%)$, which were frequently captured in multicatch events (up to 200 birds in a single event).

According to onboard observations, bycatch primarily occurred from March to July (Fig. 5a), being especially high in May. This seasonal pattern was roughly consistent with the fishermen's reports, which also showed low levels of bycatch in summer and early autumn, and a small peak in winter (Fig. 5b).

Seabird bycatch was greater in the daytime $(\mathrm{N}=53$ birds, Fig. 6), mainly influenced by a massive catch registered at midday (45 Puffinus spp. in 1 setting).

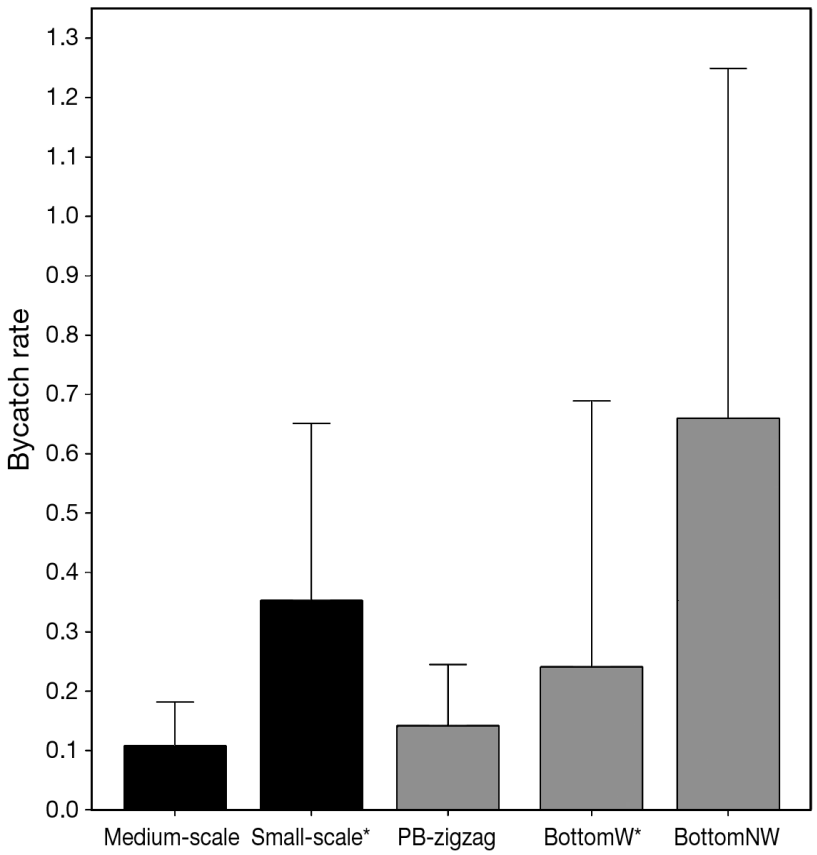

Fig. 4. Bycatch rate (birds caught per 1000 hooks, mean \pm $95 \% \mathrm{CI}$ ) according to both the vessel type (left) and the most common gear configurations (right) in the study area. Vessel type includes medium-scale ( $\mathrm{N}=103$ fishing trips) and smallscale vessels $(N=117)$ of the study area. Gear configuration includes PB-zigzag (Piedra-Bola in zigzag, $\mathrm{N}=73$ ), BottomW (bottom-weight, longline with only weights attached along the mainline, $\mathrm{N}=56$ ), and BottomNW (bottom-no weights, longline without either weights or floats, $\mathrm{N}=42$ ). The PBpyramidal configuration was not considered here due to low sample size. ${ }^{*}$ The massive catch of small shear-waters is not included in the data 
Settings during the night resulted in fewer catches $(\mathrm{N}=7)$ that mainly occurred during full moon $(71 \%)$. In this case, the species most affected were nocturnal feeders, such as Scopoli's shearwaters $(\mathrm{N}=2)$ and Audouin's gulls $(\mathrm{N}=2)$. However, Balearic shearwaters were also caught at night $(\mathrm{N}=3)$. Additionally, a higher bycatch rate of shearwaters and gulls was found when a mix of cephalopods and fish were used as bait (Fig. 7).

The annual mortality estimated for the mediumscale vessels from Catalonia was 357 (126-642) birds, while for Minorca's small-scale vessels it was 675 (148-1556) birds. Therefore, considering both areas together, we obtained a minimum annual mortality for the Balearic Sea of 1032 (274-2198) birds in the setting operations, including 683 (46-1818) Scopoli's shearwaters, 123 (0-278) Balearic shearwaters and 35 (0-85) Mediterranean shearwaters.

\section{Susceptibility to bycatch}

The proportions of species of birds observed following the vessels differed from the proportion of birds caught (Table 7, $\chi^{2}=53.47, \mathrm{df}=7, \mathrm{p}<0.001$ ) That is, shearwater species (Scopoli's shearwater: $\chi^{2}=4.62$, df $=1, \mathrm{p}<0.05$; and Puffinus spp.: $\chi^{2}=$ 29.48, df $=1, \mathrm{p}<0.001$ ) and gannets Morus bassanus $\left(\chi^{2}=4.72, \mathrm{df}=1, \mathrm{p}<0.05\right)$ were substantially more frequently caught than expected. In contrast, yellow- legged gulls were less often caught than expected from their attendance $\left(\chi^{2}=14.53, \mathrm{df}=1, \mathrm{p}<0.001\right)$. Likewise, the proportion of attacks on baited hooks obtained for each species also differed from the proportion of birds caught $\left(\chi^{2}=18.12\right.$, df $\left.=7, \mathrm{p}<0.05\right)$. Catches of Puffinus spp. $\left(\chi^{2}=4.61 .49\right.$, df $\left.=1, \mathrm{p}<0.05\right)$ and gannets $\left(\chi^{2}=10.07, \mathrm{df}=1, \mathrm{p}<0.01\right)$ occurred more often than expected from their proportion of attacks. However, the proportion of catches of Scopoli's shearwater was lower compared to the relative frequency of their attacks $\left(\chi^{2}=4.21, \mathrm{df}=1, \mathrm{p}<0.05\right)$.

On the other hand, there was no difference in the proportion of birds caught in each longline type from their attendance $\left(\chi^{2}=0.06\right.$, df $\left.=3, p=0.99\right)$ and the attacks observed $\left(\chi^{2}=0.01, \mathrm{df}=3, \mathrm{p}=0.99\right)$.

\section{DISCUSSION}

Our study confirms that artisanal demersal longliners in the Balearic Sea cause high seabird mortality. This is particularly so for Scopoli's shearwaters around the Balearic Islands and, most importantly, for small (Puffinus) shearwaters off the Iberian Peninsula, often involving multi-catch events. We also provide detailed information on the fishery, which is diverse in specific gear configurations and fishing strategies, and assess which are the main factors influencing seabird bycatch. This is a first step towards understanding seabird bycatch and develop-

Table 6. Number of birds reported by fishermen (maximum birds registered per event is indicated in brackets) in each year of the study period ( $\mathrm{N}=739$ birds, 15 boats). Total events = number of fishing days in which bird catches were reported. Total bycatch = number of birds bycaught including those events registered in the on-board observations. Some species could not be identified to species level, so these are grouped by genus or in a general group. $\left({ }^{*}\right)$ indicates small-scale vessels. 2015 is comprised of January only. Species binomials are given in Table 3

\begin{tabular}{|c|c|c|c|c|c|c|c|}
\hline Species & 2011 & 2012 & 2013 & 2014 & 2015 & $\begin{array}{c}\text { Total } \\
\text { events }\end{array}$ & $\begin{array}{c}\text { Total } \\
\text { bycatch }\end{array}$ \\
\hline Balearic shearwater & - & 3 & 5 & $11(3)$ & - & 19 & 97 \\
\hline Mediterranean shearwater & - & - & - & $14(4)$ & - & 6 & 49 \\
\hline Scopoli's shearwater & 1 & $30(12)$ & $1+30^{*}(30)$ & $49(20)+12^{*}(9)$ & - & 20 & 166 \\
\hline \multicolumn{8}{|l|}{ Unidentified shearwaters: } \\
\hline Puffinus spp. & - & $18(8)$ & $20(10)$ & $130 *(130)+33(30)$ & $20(20)$ & 12 & 269 \\
\hline Puffinus and Calonectris & $200^{\mathrm{a}}(200)$ & $38(38)$ & - & $8(4)+80^{*}(80)$ & - & 3 & 215 \\
\hline Puffinus or Calonectris & - & - & - & $8(4)$ & - & 4 & 8 \\
\hline Northern gannet & 1 & 3 & $5(2)$ & - & - & 8 & 10 \\
\hline Audouin's gull & 1 & $3(2)$ & $10(4)$ & - & - & 8 & 18 \\
\hline Mediterranean gull & - & - & $4(4)$ & 1 & - & 2 & 5 \\
\hline Sandwich tern & - & - & - & 1 & - & 1 & 1 \\
\hline Unidentified gulls & - & - & 2 & - & - & 1 & 2 \\
\hline Yellow-legged gull & - & - & - & - & - & - & 7 \\
\hline Black-legged kittiwake & - & - & - & - & - & $\begin{array}{c}- \\
\text { Total }\end{array}$ & $\begin{array}{c}2 \\
849\end{array}$ \\
\hline
\end{tabular}



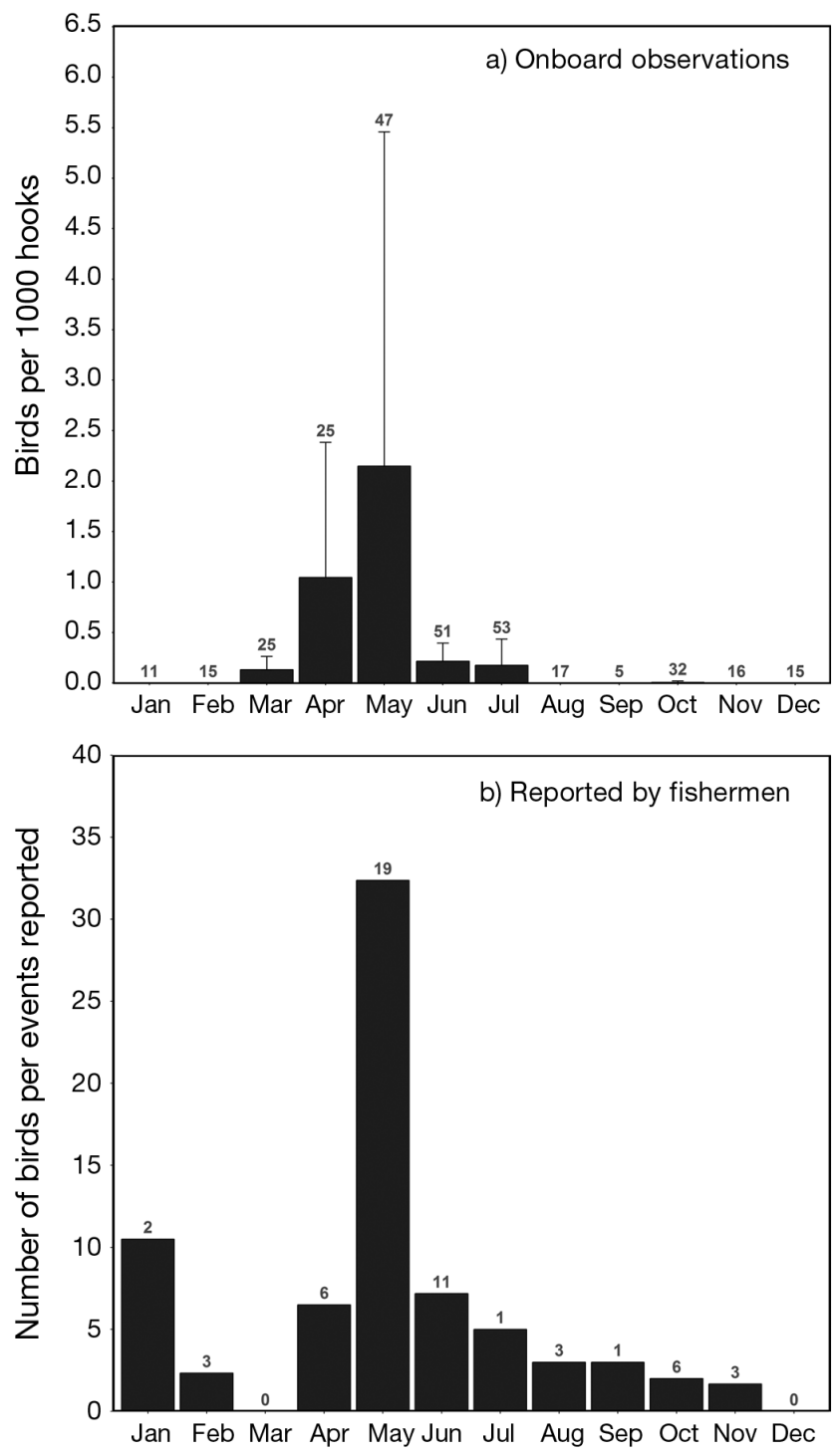

Fig. 5. Monthly occurrence of bycatch according to (a) onboard observations data (mean bycatch rate $+95 \% \mathrm{CI}$ ) and (b) birds reported by fishermen (raw numbers). Numbers above bars specify (a) the number of settings observed and (b) the number of events reported

ing appropriate mitigation measures. However, the high diversity of configurations and strategies makes it difficult to accurately estimate bycatch or to identify easy mitigation solutions applicable to the whole fleet.

The overall average bycatch rate obtained in this study for the demersal longline fishery was 0.58 (0.13-1.37) birds per 1000 hooks. This rate is within the range of previous studies on demersal longliners from the Columbretes Islands (0.16-0.69 birds per 1000 hooks, Belda \& Sánchez 2001), and higher than that found in previous studies in the pelagic longlin-

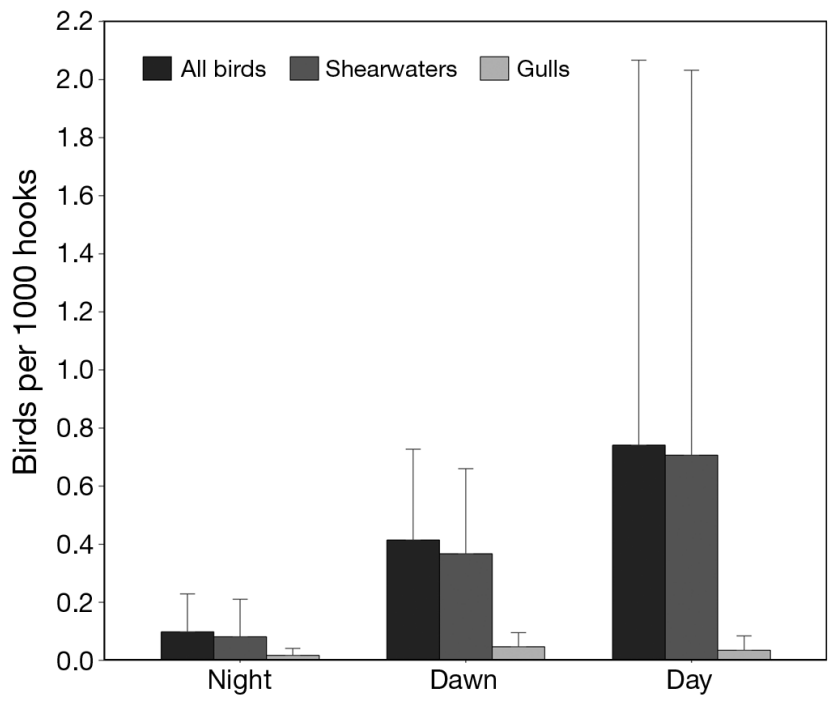

Fig. 6. Bycatch rates $(+95 \% \mathrm{CI})$ in demersal longliners in relation to the 3 different setting time intervals considered: night $(\mathrm{N}=51$ settings); dawn $(\mathrm{N}=150, \pm 1 \mathrm{~h}$ from sunrise); and daytime $(\mathrm{N}=115)$. Data are grouped by all bird species, shearwaters only (Calonectris diomedea + Puffinus spp.) and gulls only (Larus michahellis, L. audouinii, Rissa tridactyla)

ers from the western Mediterranean (0.01-0.05 birds per 1000 hooks, Barcelona et al. 2010, Valeiras \& Camiñas 2003; 0.25 birds per 1000 hooks, Belda \& Sánchez 2001). In previous studies, the most caught species were Scopoli's shearwater and yellow-legged gull, while catches of small shearwaters (Puffinus spp.) were comparatively low (Belda \& Sánchez 2001, Valeiras \& Camiñas 2003, Barcelona et al. 2010, Laneri et al. 2010). In contrast, our study reports for the first time high bycatch rates in demersal longlines of 2 globally threatened seabirds, namely the Critically Endangered Balearic shearwater and the Vulnerable Mediterranean shearwater (BirdLife International 2017), confirming previous suspicions (Arcos et al. 2008, ICES 2013). Along with Scopoli's shearwater, these small shearwaters were the most commonly caught by demersal longliners in the Balearic Sea, particularly on the Catalan continental shelf, where important foraging grounds are located (Arcos et al. 2012, Péron et al. 2013, Meier et al. 2015). This high incidence of capture is subject to irregular catches, often involving dozens to even hundreds of individuals, thus complicating the detection and quantification of the problem. Demographic studies carried out on these 2 Puffinus species, Balearic and Mediterranean shearwaters, showed a severe decline in their populations related to high mortality at sea (Oppel et al. 2011, Genovart et al. 2016), altogether indicating that incidental catches likely represent the most relevant cause of their decline. 


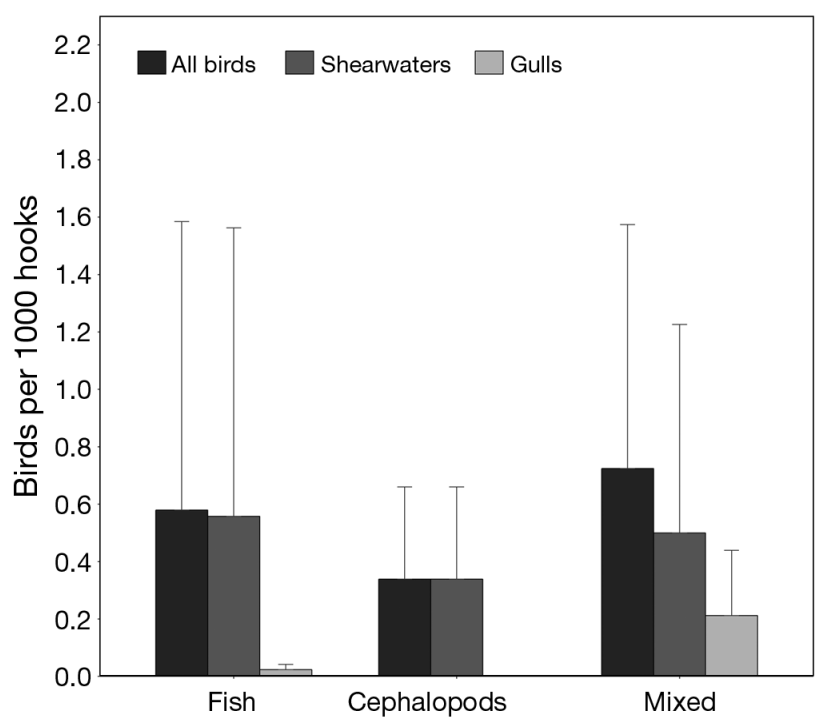

Fig. 7. Mean numbers of birds bycaught (+ 95\% CI) in demersal longliners in relation to bait category: fish $(\mathrm{N}=150$ settings), cephalopods $(\mathrm{N}=106)$ and mixed $(\mathrm{N}=39$, fish + cephalopods). Data are grouped by all bird species, shearwaters only (Calonectris diomedea + Puffinus spp.) and gulls only (Larus michahellis, L. audouinii, Rissa tridactyla)

We estimated that at least 274 to 2198 birds are killed annually by the demersal longliners in the Balearic Sea. However, this number should be considered a gross underestimation because (1) not all birds caught during settings are retrieved during gear hauling due to carcasses falling off the hooks,

Table 7. Bycatch susceptibility of the different seabird species (expressed as the \% of birds potentially bycaught) and in different longline configurations by considering the proportion of birds caught ( $\mathrm{N}=64$ birds) in relation to the birds attending vessels and to the birds attacking bait. Proportions are based on numbers registered during on-board observations. The massive catch event of small shearwaters (Table 5 ) and the data from the Piedra-Bola (PB)-pyramidal gear to target pelagic fish are not included in the analysis. ${ }^{*} \mathrm{p}<0.05$, ${ }^{* *} \mathrm{p}<0.01$. Species binomials are given in Table 3

\begin{tabular}{|c|c|c|c|}
\hline \multirow[b]{2}{*}{ Species/gear } & \multicolumn{2}{|c|}{$\begin{array}{c}\% \text { of birds potentially } \\
\text { bycaught }\end{array}$} & \multirow[t]{2}{*}{$\begin{array}{c}\% \text { of birds } \\
\text { caught }\end{array}$} \\
\hline & $\begin{array}{c}\text { By } \\
\text { attendance }\end{array}$ & $\begin{array}{c}\text { By } \\
\text { attacks }\end{array}$ & \\
\hline Scopoli's shearwater & $39.50^{*}$ & $60.05^{*}$ & 50.00 \\
\hline Puffinus spp. & $11.21^{* *}$ & $19.83^{*}$ & 28.19 \\
\hline Yellow-legged gull & $28.06^{* *}$ & 8.46 & 10.94 \\
\hline Audouin's gull & 12.57 & 8.13 & 6.25 \\
\hline Black-legged kittiwake & 2.06 & 2.07 & 3.13 \\
\hline Northern gannet & $0.33^{*}$ & $0.19^{* *}$ & 1.56 \\
\hline Mediterranean gull & 5.58 & 0.61 & 0 \\
\hline Sandwich tern & 0.70 & 0.66 & 0 \\
\hline PB-zigzag & 0.35 & 0.31 & 0.30 \\
\hline PB-pyramidal & 0.02 & 0.00 & 0 \\
\hline Bottom-weights & 0.18 & 0.27 & 0.26 \\
\hline Bottom-no weights & 0.44 & 0.40 & 0.42 \\
\hline
\end{tabular}

becoming untangled from the line or being removed by scavenging marine species, which may result in an underestimation by more than half (Gales et al. 1998, Gilman et al. 2003, Brothers et al. 2010); (2) it is difficult to detect mass catch events of birds through on-board observer programmes with low coverage, due to their stochastic nature; and (3) the estimate is solely based on catches occurring on small-scale vessels from the Minorca coast and medium-scale longliners from the Catalan coast, as these were the only areas where it was possible to obtain reliable fishing effort data. Especially, there is a lack of information about the fishing effort of the small-scale vessels operating in the area, which hampers obtaining an accurate estimate of the mortality caused by this fishery.

We found that susceptibility to bycatch as indicated by the proportion of birds attending vessels and those attacking the bait, greatly differed among species; in particular, it was greater in the shearwater species and gannets, and lower in the more common yellow-legged gull. This taxon-specific risk varies with the feeding ecology and behaviour of each species (Weimerskirch et al. 2000). Indeed, the lower number of bait attacks by gull species, despite being the most common birds attending longline vessels, is likely due to their lower diving capabilities, which limits their access to the baited hooks once these sink into the water. In contrast, shearwaters are strong divers that can reach the baited hooks even when these are several metres underwater, reaching depths down to $28 \mathrm{~m}$ (Meier et al. 2015), thus increasing their bycatch risk. Likewise, in the case of the northern gannet, the species also showed a high susceptibility to being caught in longlines due to its high deep-diving ability (Ropert-Coudert et al. 2009), although relatively few catches were recorded due to its relatively low occurrence behind vessels.

Season was the most important factor influencing seabird attacks on baited hooks. In addition, the setting time also had a large effect on attack occurrence probability. Other factors such as type and size of the bait, wind conditions, distance between weights and number of hooks set also had a significant, albeit lower, influence on the seabird interaction with longline vessels. When considering only Scopoli's shearwater, distance to the colony became an additional factor of relevance, whereas bait type and the number of hooks had no significant effects.

Previous studies in the area reported higher seabird bycatch during the breeding period (Belda \& Sánchez 2001, García-Barcelona et al. 2010, Laneri et al. 2010). We found that the number of attacks on bait was greatest in spring (April to June), when most Mediterranean seabirds are breeding. The spring 
also had the highest level of seabird bycatch registered from onboard observations as well as from fishermen's reports. In the case of the Puffinus species, this season coincides with their chick-rearing period. In Scopoli's shearwater, it includes both the prelaying and incubation periods. These results coincide with those by Laneri et al. (2010), but differ from other studies carried out in the western Mediterranean, which found greater catches of Scopoli's shearwaters during the chick-rearing and fledging periods (October; Belda \& Sánchez 2001, García-Barcelona et al. 2010, Báez et al. 2014). These differences might be related to small to medium-scale geographical differences between these groups of studies, matching different spatiotemporal distribution patterns of the shearwaters, and highlight the relevance of applying a local approach to management. We can infer from this that an appropriate seasonal regulation of the fishing effort might significantly reduce seabird bycatch in the study area, although it could also entail significant economic losses for the artisanal fishermen since this period coincides with the most productive months of the fishery.

Settings during daylight hours increased the attack occurrence probability, and it was further increased when longlines were set at dawn, agreeing with previous studies (e.g. Belda \& Sánchez 2001, Laneri et al. 2010). This is because seabird species in the Mediterranean are mainly diurnal and are particularly active at dawn and dusk (Passos et al. 2010, Dias et al. 2012, Meier et al. 2015). Concordantly, incidental catches were most frequent at dawn, although catches can also be high during daytime. Several studies recommend night setting as the most suitable method for reducing seabird bycatch in multiple types of longline fisheries (Brothers et al. 1999b, Belda \& Sánchez 2001, Løkkeborg 2011). However, its effectiveness may vary depending on the seabird community occurring in a particular area. Some seabirds are active feeders at night and could also be caught during this period, especially on nights with bright moonlight or a full moon (Brothers et al. 1999b, Belda \& Sánchez 2001, Delord et al. 2010). In this study, we found that seabird interactions were significantly reduced at night, with only $9 \%$ of all catches reported during this time period. This result is particularly relevant for the Critically Endangered Balearic shearwater, as this species is mostly active in daylight, specifically during the crepuscular hours (Meier et al. 2015), so that catches at night are less likely. Indeed, only 3 of 64 Puffinus shearwaters caught during the onboard observations were Balearic shearwaters captured at night, all of them on the same boat in 2 consecutive days, coinciding with a full moon. Thus, night setting appears to be a promising mitigation measure in the Mediterranean. Moreover, it could be relatively easy to enforce effectively compared to other potential mitigation measures, although it might reduce catches of target species and lead to economic losses for fishermen (Brothers et al. 1999a, Sánchez \& Belda 2003). Careful experimental approaches should assess the practical applicability of night setting and quantify its effects on target species as well as on other non-target species of fish potentially sensitive to longlining bycatch (e.g. elasmobranches), and confirm the efficacy of this mitigation method in different moonlight conditions.

Another important factor influencing attacks was the type of bait used. The number of attacks was greater when fishermen used mixed bait and cephalopods than when they used fish bait. Mixed bait also increased the bycatch rate, possibly because different species tend to select different bait types (Trebilco et al. 2010). However, this effect was largely due to a higher capture of gulls. On the other hand, the attack occurrence probability was greater for hooks baited only with fish than those using other types of bait. When considering only Scopoli's shearwater, however, we did not find a significant effect of the type of bait used. The number of attacks also increased when fishermen used bait larger than $10 \mathrm{~cm}$, which agrees with the prey size selected by shearwaters (Arcos 2001) and Audouin's and yellowlegged gulls when feeding on trawler discards in the western Mediterranean (Arcos et al. 2001).

Wind conditions at setting also had an important influence on the attacks. In general, the abundance and the occurrence of attacks increased on windy days. Some fishermen also reported that seabird catches increased on very windy fishing days (pers. comm.). Previous studies evaluating effects of weather conditions on seabird bycatch showed contrasting results. Some also detected an increase in seabird interactions under bad weather conditions (Brothers et al. 1999b, Weimerskirch et al. 2000, Delord et al. 2010), since water turbulence may keep baited hooks near the surface and therefore available to seabirds for a longer time, thus increasing bycatch risk. Alternatively, increased interactions could also be due to a greater difficulty for birds to find and capture their natural prey under these conditions, leading to an increased interaction with fishing vessels. In contrast, other studies did not detect any effect of wind speed on seabird bycatch (Klaer \& Polacheck 1998) or found that its influence varied from species to species (Dietrich et al. 2009). 
Specific gear configuration, namely the distance between weights, also had an important influence on seabird bycatch; increased distances led to a greater likelihood of bait attacks and, in the case of Scopoli's shearwater, it increased the number of attacks. This makes sense, as greater distances and lighter weights slow the longline sink rate (Robertson et al. 2007) and therefore increase seabird access to the baited hooks. We found these characteristics in the bottom longliners used by small-scale vessels in the study area. Despite this, we did not find significant differences in bycatch susceptibility among longline types. However, bycatch rates were higher in the bottom longlines, especially those that did not have weights attached. This may be explained by the greater exposure of the bait to seabirds, which could increase the attacks and in turn the risk of being caught. Nevertheless, to properly evaluate the accessibility of the baited hooks to seabirds it would be necessary to measure the sink rate of the different longline types used.

Setting the longlines near breeding colonies increased the probability of Scopoli's shearwaters attacking baits, an effect previously reported in several other studies (Weimerskirch et al. 2000, Dietrich et al. 2009, Trebilco et al. 2010). However, the number of shearwater attacks did not change significantly with distance. In fact, $17 \%$ of the catches recorded for this species occurred at more than $70 \mathrm{~km}$ from the nearest breeding colony. This result shows that the risk of mortality in this species can also be high in fishing grounds far from their breeding colonies.

The number of hooks set increased the attacks if we considered all seabird species. In general, previous studies found an increase in the incidental mortality with the number of hooks deployed per set (Delord et al. 2010, Báez et al. 2014), but its influence may differ among species (Dietrich et al. 2009). Nonetheless, other studies did not assess its effect, as they considered the number of hooks set as a simple measure of the fishing effort (Belda \& Sánchez 2001, Trebilco et al. 2010).

Overall, we found that the likelihood of attacks at line setting was greater on days when trawlers were not operating, although the importance of this factor was relatively low compared to the other factors. Nevertheless, this result agrees with previous studies carried out in the western Mediterranean, which found an increase in the probability of birds attending longliners and/or greater incidental catches during non-working days of the trawlers (GarcíaBarcelona et al. 2010, Laneri et al. 2010, Báez et al. 2014, Soriano-Redondo et al. 2016). Trawler discards have a great influence on foraging behaviour of scavenging species (Bartumeus et al. 2010, Cama et al. 2013, Bécares et al. 2015), so the absence of trawler activity can induce birds to search for alternative food resources, such as bait used by longline vessels.

\section{CONCLUSIONS}

Our results show that demersal longline fisheries catch high numbers of the 3 endemic species of shearwater in the Mediterranean, all of them of conservation concern, calling for urgent and effective action to reduce their bycatch rates. The present study provides insight on the factors influencing bycatch in the Balearic Sea, which should be taken into account when designing the most appropriate mitigation measures for the region. It also shows that setting at night and implementing temporal closure of the fishery during the most conflictive months are the most promising strategies to reduce seabird bycatch. Nevertheless, further studies directed toward the effectiveness of these strategies to reduce seabird bycatch and their potential effects on fishing activity are desirable. Streamer lines and the increase of bait sink rate by adding weight to the line, or a combination of different mitigation measures, have also been proven to be very effective in some demersal fisheries from other regions (Brothers et al. 1999b, Dietrich et al. 2008, Løkkeborg 2011, Melvin et al. 2013), but should be carefully evaluated in the Mediterranean, since the diving capability of the 3 shearwater species may render these mitigation methods less effective.

Acknowledgements. We are grateful to the skippers and crews of fishing vessels that voluntarily collaborated in this project. We thank Cristina Aranguren, Èric Domínguez, Lluïsa Ferrer, Manel Mamano, Pau Marquès, Neus Matamalas, Toni Mulet, Blanca Sarzo, Adriana Rodríguez, Oriol Torres and David Torrens for making observations on the fishing vessels, and Rosario Allué (Generalitat de Catalunya) and Francesc Roselló (Govern de les Illes Balears) for providing fishing effort data. We also thank Oliver Yates from RSPB and 2 anonymous refereers for their helpful comments and recommendations, and to Andy Smith and Bob Bonn for providing language help. This study was funded by the Fundación Biodiversidad (18PCA4328, 2012-13; 2013-14; 2014-15) and the Spanish government (CGL2009-11278/BOS, CGL2013-42585-P), and also received financial support from the EC LIFE+ Project INDEMARES. V.C. was supported by a $\mathrm{PhD}$ grant from the Generalitat de Catalunya (FI/DGR/2011), and J.M.A. was partially supported by the Segré Fondation through the BirdLife Seabird Task Force. 


\section{LITERATURE CITED}

Anderson ORJ, Small CJ, Croxall JP, Dunn EK, Sullivan BJ, Yates O, Black A (2011) Global seabird bycatch in longline fisheries. Endang Species Res 14:91-106

Arcos JM (2001) Foraging ecology of seabirds at sea: significance of commercial fisheries in the NW Mediterranean. $\mathrm{PhD}$ thesis, University of Barcelona

Arcos JM, Oro D, Sol D (2001) Competition between yellowlegged gull Larus cachinnans and Audouin's gull Larus audouinii associated with commercial fishing vessels: the influence of season and fishing fleet. Mar Biol 139: 807-816

Arcos JM, Louzao M, Oro D (2008) Fisheries ecosystem impacts and management in the Mediterranean: seabirds point of view. In: Nielsen J, Dodson JJ, Friedland K, Hamon TR, Musick J, Verspoor E (eds) Reconciling fisheries with conservation. Proc $4^{\text {th }}$ World Fisheries Congress. American Fisheries Society Symposium 49. American Fisheries Society, Bethesda, MD, p 587-596

Arcos JM, Bécares J, Villero L, Rodríguez B, Ruiz A (2012) Assessing the location and stability of foraging hotspots for pelagic seabirds: an approach to identify marine Important Bird Areas (IBAs) in Spain. Biol Conserv 156: 30-42

* Báez JC, García-Barcelona S, Mendoza M, Ortiz de Urbina JM, Real R, Macías D (2014) Cory's shearwater by-catch in the Mediterranean Spanish commercial longline fishery: implications for management. Biodivers Conserv 23: 661-681

Barcelona SG, Ortiz de Urbina JM, de la Serna JM, Alot E, Macías D (2010) Seabird bycatch in Spanish Mediterranean large pelagic longline fisheries, 2000-2008. Aquat Living Resour 23:363-371

Bartumeus F, Giuggioli L, Louzao M, Bretagnolle V, Oro D, Levin SA (2010) Fishery discards impact on seabird movement patterns at regional scales. Curr Biol 20: 215-222

Bécares J, García-Tarrasón M, Villero D, Bateman S and others (2015) Modelling terrestrial and marine foraging habitats in breeding Audouin's gulls Larus audouinii: timing matters. PLOS ONE 10:e0120799

Belda EJ, Sánchez A (2001) Seabird mortality on longline fisheries in the Western Mediterranean: factors affecting bycatch and proposed mitigating measures. Biol Conserv 98:357-363

BirdLife International (2017) IUCN Red List for birds. http:// www.birdlife.org

* Brothers N (1991) Albatross mortality and associated bait loss in the Japanese longline fishery in the southern ocean. Biol Conserv 55:255-268

Brothers N, Cooper J, Løkkeborg S (1999a) The incidental catch of seabirds by longline fisheries: worldwide review and technical guidelines for mitigation. Food and Agriculture Organization of the United Nations, Rome

Brothers N, Gales R, Reid T (1999b) The influence of environmental variables and mitigation measures on seabird catch rates in the Japanese tuna longline fishery within the Australian Fishing Zone, 1991-1995. Biol Conserv 88:85-101

Brothers N, Duckworth AR, Safina C, Gilman EL (2010) Seabird bycatch in pelagic longline fisheries is grossly underestimated when using only haul data. PLOS ONE 5:e12491
Burnham KP, Anderson DR (2002) Model selection and multimodel inference: a practical information-theoretic approach. Springer, New York, NY

Cama A, Bort J, Christel I, Vieites DR, Ferrer X (2013) Fishery management has a strong effect on the distribution of Audouin's gull. Mar Ecol Prog Ser 484:279-286

Cooper J, Baccetti N, Belda EJ, Borg JJ, Oro D, Papakonstantinou C, Sánchez A (2003) Seabird mortality from longline fishing in the Mediterranean Sea and Macaronesian waters: a review and a way forward. Sci Mar 67(Suppl 2):57-64

* Croxall JP, Butchart SHM, Lascelles B, Stattersfield AJ, Sullivan B, Symes A, Taylor P (2012) Seabird conservation status, threats and priority actions: a global assessment. Bird Conserv Int 22:1-34

* Delord K, Gasco N, Barbraud C, Weimerskirch H (2010) Multivariate effects on seabird bycatch in the legal Patagonian toothfish longline fishery around Crozet and Kerguelen Islands. Polar Biol 33:367-378

* Dias MP, Granadeiro JP, Catry P (2012) Working the day or the night shift? Foraging schedules of Cory's shearwaters vary according to marine habitat. Mar Ecol Prog Ser 467: 245-252

*Dietrich KS, Melvin EF, Conquest L (2008) Integrated weight longlines with paired streamer lines - best practice to prevent seabird bycatch in demersal longline fisheries. Biol Conserv 141:1793-1805

Dietrich KS, Parrish JK, Melvin EF (2009) Understanding and addressing seabird bycatch in Alaska demersal longline fisheries. Biol Conserv 142:2642-2656

Fletcher D, MacKenzie D, Villouta E (2005) Modelling skewed data with many zeros: a simple approach combining ordinary and logistic regression. Environ Ecol Stat 12:45-54

Gales R, Brothers N, Reid T (1998) Seabird mortality in the Japanese tuna longline fishery around Australia, 19881995. Biol Conserv 86:37-56

García-Barcelona S, Macías D, Ortiz de Urbina JM, Estrada A, Real R, Báez JC (2010) Modelling abundance and distribution of seabird by-catch in the Spanish Mediterranean longline fishery. Ardeola 57: 65-78

Genovart M, Arcos JM, Álvarez D, McMinn M and others (2016) Demography of the critically endangered Balearic shearwater: the impact of fisheries and time to extinction. J Appl Ecol 53:1158-1168

* Gilman E (2001) Integrated management to address the incidental mortality of seabirds in longline fisheries. Aquat Conserv 11:391-414

Gilman E, Boggs C, Brothers N (2003) Performance assessment of an underwater setting chute to mitigate seabird bycatch in the Hawaii pelagic longline tuna fishery. Ocean Coast Manag 46:985-1010

Gilman E, Brothers N, Kobayashi DR (2005) Principles and approaches to abate seabird by-catch in longline fisheries. Fish Fish 6:35-49

ICES (International Council for the Exploration of the Sea) (2013) Report of the Workshop to Review and Advise on Seabird Bycatch (WKBYCS), 14-18 October 2013, Copenhagen, Denmark. ICES CM 2013/ACOM:77-79. ICES, Copenhagen

Inchausti P, Weimerskirch H (2001) Risks of decline and extinction of the endangered Amsterdam albatross and the projected impact of long-line fisheries. Biol Conserv 100:377-386 
Klaer NL, Polacheck T (1998) The influence of environmental factors and mitigation measures on by-catch rates of seabirds by Japanese longline fishing vessels in the Australian region. Emu 98:305-316

Laneri K, Louzao M, Martínez-Abraín A, Arcos JM and others (2010) Trawling regime influences longline seabird bycatch in the Mediterranean: new insights from a small-scale fishery. Mar Ecol Prog Ser 420:241-252

Lewison RL, Crowder LB (2003) Estimating fishery bycatch and effects on a vulnerable seabird population. Ecol Appl 13:743-753

Lewison RL, Crowder LB, Wallace BP, Moore JE and others (2014) Global patterns of marine mammal, seabird, and sea turtle bycatch reveal taxa-specific and cumulative megafauna hotspots. Proc Natl Acad Sci USA 111: 5271-5276

Løkkeborg S (2011) Best practices to mitigate seabird bycatch in longline, trawl and gillnet fisheries-efficiency and practical applicability. Mar Ecol Prog Ser 435:285-303

Martí R, Del Moral JC (2013) Atlas de las aves reproductoras en España. Dirección General de Conservación de la Naturaleza-Sociedad Española de Ornitología, Madrid

Meier RE, Wynn RB, Votier SC, McMinn Grivé M and others (2015) Consistent foraging areas and commuting corridors of the critically endangered Balearic shearwater Puffinus mauretanicus in the northwestern Mediterranean. Biol Conserv 190:87-97

Melvin EF, Guy TJ, Read LB (2013) Reducing seabird bycatch in the South African joint venture tuna fishery using bird-scaring lines, branch line weighting and nighttime setting of hooks. Fish Res 147:72-82

Oppel S, Raine AF, Borg JJ, Raine H, Bonnaud E, Bourgeois K, Breton AR (2011) Is the Yelkouan shearwater Puffinus yelkouan threatened by low adult survival probabilities? Biol Conserv 144:2255-2263

Passos C, Navarro J, Giudici A, González-Solís J (2010) Effects of extra mass on the pelagic behavior of a seabird. Auk 127:100-107

Péron C, Grémillet D (2013) Tracking through life stages: adult, immature and juvenile autumn migration in a long-lived seabird. PLOS ONE 8:e72713

Péron C, Grémillet D, Prudor A, Pettex E and others (2013) Importance of coastal Marine Protected Areas for the conservation of pelagic seabirds: the case of the vulnerable yelkouan shearwaters in the Mediterranean Sea. Biol Conserv 168:210-221

Robertson G, Moreno CA, Crujeiras J, Wienecke B, Gandini P, Mcpherson G, Seco Pon JP (2007) An experimental assessment of factors affecting the sink rates of spanishrig longlines to minimize impacts on seabirds. Aquat Conserv 17:S102-S121

Editorial responsibility: Rory Wilson,

Swansea, UK
Ropert-Coudert Y, Daunt F, Kato A, Ryan PG and others (2009) Underwater wingbeats extend depth and duration of plunge dives in northern gannets Morus bassanus. J Avian Biol 40:380-387

Sánchez A, Belda EJ (2003) Bait loss caused by seabirds on longline fisheries in the northwestern Mediterranean: Is night setting an effective mitigation measure? Fish Res 60:99-106

* Soriano-Redondo A, Cortés V, Reyes-González JM, Guallar S and others (2016) Relative abundance and distribution of fisheries influence risk of seabird bycatch. Sci Rep 6: 37373

*Tasker ML, Camphuysen KCJ, Cooper J, Garthe S, Montevecchi W, Montevecchi W, Blaber SJM (2000) The impacts of fishing on marine birds. ICES J Mar Sci 57: 531-547

*Trebilco R, Gales R, Lawrence E, Alderman R, Robertson G, Baker GB (2010) Characterizing seabird bycatch in the eastern Australian tuna and billfish pelagic longline fishery in relation to temporal, spatial and biological influences. Aquat Conserv 20:531-542

Valeiras J, Camiñas JA (2003) The incidental capture of seabirds by Spanish drifting longline fisheries in the western Mediterranean Sea. Sci Mar 67:65-68

*Wanless RM, Ryan PG, Altwegg R, Angel A, Cooper J, Cuthbert R, Hilton GM (2009) From both sides: dire demographic consequences of carnivorous mice and longlining for the critically endangered Tristan albatrosses on Gough Island. Biol Conserv 142:1710-1718

Weimerskirch H (2002) Seabird demography and its relationship with the marine environment. In: Schreiber EA, Burger J (eds) Biology of marine birds. CRC Press, Boca Raton, FL, p 115-136

Weimerskirch H, Brothers N, Jouventin P (1997) Population dynamics of wandering albatross Diomedea exulans and Amsterdam albatross $D$. amsterdamensis in the Indian Ocean and their relationships with long-line fisheries: conservation implications. Biol Cons 79:257-270

*Weimerskirch H, Capdeville D, Duhamel G (2000) Factors affecting the number and mortality of seabirds attending trawlers and long-liners in the Kerguelen area. Polar Biol 23:236-249

Welsh AH, Cunningham RB, Donnelly CF, Lindenmayer DB (1996) Modelling the abundance of rare species: statistical models for counts with extra zeros. Ecol Model 88: 297-308

Zuur AF, Leno EN, Walker NJ, Saveliev AA, Smith GM (2009) Mixed effects models and extensions in ecology with R. Springer, New York, NY

* Zuur AF, Leno EN, Elphick CS (2010) A protocol for data exploration to avoid common statistical problems. Methods Ecol Evol 1:3-14

Submitted: July 27, 2016; Accepted: December 18, 2016 Proofs received from author(s): February 2, 2017 